\title{
Organizing physics teacher professional education around productive habit development: A way to meet reform challenges
}

\author{
Eugenia Etkina, ${ }^{1}$ Bor Gregorcic, ${ }^{2, *}$ and Stamatis Vokos ${ }^{3}$ \\ ${ }^{1}$ Graduate School of Education, Rutgers University, New Brunswick, New Jersey 08904, USA \\ ${ }^{2}$ Department of Physics and Astronomy, Uppsala University, P.O. Box 516, 75120 Uppsala, Sweden \\ ${ }^{3}$ Department of Physics, California Polytechnic State University, San Luis Obispo, California 93407, USA
}

(Received 3 June 2016; published 30 January 2017)

\begin{abstract}
Extant literature on teacher preparation suggests that preservice teachers learn best when they are immersed in a community that allows them to develop dispositions, knowledge, and practical skills and share with the community a strong vision of what good teaching entails. However, even if the requisite dispositions, knowledge, and skills in pursuing the shared vision of good teaching are developed, the professional demands on a teacher's time are so great out of, and so complex during class time that if every decision requires multiple considerations and deliberations with oneself, the productive decisions might not materialize. We argue that the link between intentional decision making and actual teaching practice are teacher's habits (spontaneous responses to situational cues). Teachers unavoidably develop habits with practical experience and under the influence of knowledge and belief structures that in many ways condition the responses of teachers in their practical work. To steer new teachers away from developing unproductive habits directed towards "survival" instead of student learning, we propose that teacher preparation programs (e.g., in physics) strive to develop in preservice teachers strong habits of mind and practice that will serve as an underlying support structure for beginning teachers. We provide examples of physics teacher habits that are to be developed during the program, propose mechanisms for the development of such habits, and outline possible future research agendas around habits.
\end{abstract}

DOI: 10.1103/PhysRevPhysEducRes.13.010107

\section{INTRODUCTION}

Current national science education reform efforts at the precollege level pose serious challenges yet provide significant opportunities for physics teacher education (PTE) programs. The Next Generation Science Standards [1] and the redesigned Advanced Placement Physics test point to a different role for a physics teacher. There is an expectation that PTE graduates will enter teaching with the requisite knowledge, skills, and dispositions to be able to engage classroom communities of students in physics concept construction and computation, through immersion in the practices of the discipline. This is an ambitious vision that is accompanied by on-the-ground challenges.

One serious challenge arises from the mismatch between the actual experiences of the prospective teacher as a learner in many university physics courses and the expected experience she is to provide her own students. Many physics college courses, especially at the introductory level in which prospective teachers learn most topics relevant

\footnotetext{
*Corresponding author. bor.gregorcic@physics.uu.se

Published by the American Physical Society under the terms of the Creative Commons Attribution 3.0 License. Further distribution of this work must maintain attribution to the author $(s)$ and the published article's title, journal citation, and DOI.
}

to the precollege curriculum, are lecture-based, largeenrollment, deductive in nature (from grand principles to applications), often accompanied by step-by-step laboratory exercises in which students confirm laws of physics experimentally and account for discrepancies between their findings and theoretical predictions. Even courses that incorporate interactive engagement strategies often engage students in sense making for a relatively short proportion of the course and after students are exposed to the material by reading the textbook. Education courses, on the other hand, familiarize prospective teachers with contextual aspects of schools and students. The science methods course provides students with exposure to the literature on student-centered learning, and, perhaps, with some experience in planning, implementing, analyzing, reflecting upon, and refining one physics lesson. Student teaching in a practicing teacher's classroom provides invaluable familiarity with that teacher's routines and curriculum, school culture, interactions with parents, student behavior, etc. The onus is on the novice teacher to integrate all these pieces into a student experience that reflects the vision of the Framework for K-12 Science Education [2].

Another challenge to PTE programs arises from state endorsement regulations and course designation options, which create state contexts in which single-subject endorsements in science are impossible or professionally undesirable. Furthermore, because of the (very) small numbers of 
physics teachers prepared per U.S. institution [3], the current teacher preparation efforts almost always treat all science teachers (or even science and mathematics teachers) interchangeably. In such contexts, PTE programs provide little opportunity for aspiring teachers to develop a robust novice physics teacher's toolbox.

Yet, teaching involves habitual activity. Beginning teachers will most certainly cement routines, informed by those of others and those developed through selfreflection, or simply due to a need for survival. The recognition of the role that habits play in teacher formation goes back more than one hundred years. However, in recent times, other, smaller-in grain size-ideas (interactive engagement, student-centered strategies, formative assessment, responsive teaching) have pushed habits into the background. All teachers will eventually develop habits. These habits will then influence what kind of instruction will take place in their classroom. It stands to reason that teacher preparation programs should attend to the efficient development of productive habits, which are customized to the needs of their prospective teachers. Some such habits might be similar despite disciplinary differences. Other habits are discipline specific. Effective physics teachers need to develop both kinds. This paper is our attempt to bring to the fore the importance of productive habit formation in PTE, consider its implications for the design of PTE programs, and articulate research agendas that flow out of this proposal. Furthermore, we provide an extensive bibliography to ground future research.

In Sec. II, we review existing literature on teacher preparation, both general and in the subject of physics. In Sec. III, we make the case for teaching as a habitual activity, drawing on Dewey's ideas about habits. We propose how habits relate to three central components of teacher preparation, as they are expressed in teacher education literature. In Sec. IV, we give an illustrative list of habits that we consider productive for teachers adhering to NGSS and situate them in relation to the three central components of teacher preparation. In Sec. V, we propose possible ways of developing productive habits in preservice teachers (PSTs). In Sec. VI, we conclude the paper with implications of the proposed perspective on physics teacher preparation and suggest a possible research agenda for the future.

\section{EXTANT RESEARCH AND MODELS FOR TEACHER PREPARATION}

When one speaks of teacher learning (in the context of science teacher preparation, ${ }^{1}$ for instance), one typically thinks of knowledge and skills PSTs need to develop in order to be successful when they become in-service teachers [4].

\footnotetext{
${ }^{1}$ Although some of the claims made in this paper may be relevant for teachers of any discipline, we restrict our attention to science teacher preparation in general, and physics teacher preparation specifically.
}

Several approaches to conceptualizing teacher knowledge are discussed in the literature [5-7]. In addition to asking what a teacher should know, we also should ask what a teacher should be able to do, i.e., which teaching tasks the teacher will be required to accomplish [8]. This question offers a different perspective on teacher education in which tasks of teaching [9] are used as the starting point of discussion about teacher education [10]. We start our inquiry into teacher preparation research with the discussion of learning in general and teacher learning, in particular.

\section{A. Extant literature: Learning to be a teacher as acquisition and as participation}

Two metaphors for learning characterize the extant literature. They are significant because the design of a teacher preparation program follows from what the program leaders imagine learning to be. The two different metaphors for learning are learning as acquisition of knowledge and learning as participation in practice [11]. The former conceives knowledge as a construct of individual learners that is acquired or constructed and "resides" in an individual's brain (the cognitive, constructivist perspective), and the latter sees knowledge as "knowing" situated in real circumstances and learning as increasing participation in communities of practice (the situated, sociocultural perspective) [12-16]. The participation perspective focuses more on thinking in action and acting in particular circumstances and situations than on general knowledge.

However, as researchers have noted, choosing only one metaphor for learning, acquisition or participation, can leave us unprepared to deal with and better understand complex learning situations [11,17-19]. A comprehensive approach to understanding teacher education should therefore take into account both perspectives on learning.

It is also crucial to note that no matter how one conceives learning, and, hence, the corresponding development of knowledge and skills, their productive use by the teacher is not guaranteed [20,21]. Teachers' behavior depends heavily on their often unconscious beliefs and attitudes-what we will call dispositions (see also Sec. III)—about teaching and learning [22-24]. By dispositions, we mean those beliefs and attitudes that are relatively resistant to change, and as we will further discuss, are intimately linked to teachers' habits. Dispositions influence in critical ways how teachers interpret new information, frame situations, and guide their actions [25]. Therefore, if we wish to prepare PSTs to productively apply their knowledge and skills in real classrooms, paying attention to their dispositions is paramount $[7,26]$.

\section{B. Extant literature: Important features of successful programs of teacher preparation}

The general education literature offers plenty of recommendations on running teacher preparation [27-30], induction [29,31], and professional development [19,29,32,33] 
programs. On the other hand, studies of physics teacher preparations programs also offer numerous suggestions concerning the elements of teacher preparation [34,35]. In this section we organize main points in these two bodies of literature around three main ideas: dispositions, knowledge, and skills. ${ }^{2}$

- Attending to preservice teachers' dispositions.Prospective teachers' existing dispositions gained through their experiences as students influence their learning and guide their actions. Therefore, instead of ignoring them, we need to address PSTs' existing dispositions intentionally and critically, and further develop them in a way that will benefit their students' learning. Creating positive experience and images is an important mechanism in developing teachers' attitudes and beliefs about learning, teaching, and subject matter. General education references on this matter are given in Refs. [21,27,29,38]. In physics teacher preparation the importance of attending to dispositions can be found in Refs. [7,39-43].

- Providing sufficient duration and coherence with compelling vision.-PSTs should be expected to repeatedly observe the kind of teaching that is desired of them in order to develop dispositions that are compatible with the program's vision of good teaching. The course work and clinical practice should send coherent messages to PSTs and occur over extended periods of time [28,42]. General education references on this matter are given in Refs. [27-29]. For physics teacher preparation references in this matter, see Refs. $[7,8,41,44,45]$. The program should also consistently and persistently engage PSTs in teaching practice that reinforces the vision of the program and the values of the communities in which the program is embedded.

- Developing knowledge.-Teachers need knowledge of students and how people learn, knowledge of pedagogical methods and strategies of classroom management, and crucially, knowledge of their subject matter and domain-specific pedagogical knowledge. Teachers need to know the "key modes of inquiry and thinking" and what "key ideas are foundational in their field" [28] (p. 404) and be able to contrast them to those of other disciplines. For references addressing physics-specific knowledge for teaching, see Refs. [7,8,45-47].

- Providing opportunities for teaching experience.-It is of critical importance that PSTs get structured and repeated opportunities for clinical practice in order to develop practical skills and mechanisms for

\footnotetext{
${ }^{2}$ In the teacher education literature, lists-even lists of powerful elements (for example, Refs. [36,37])—abound. To be sure, lists of research-validated practices in which effective teachers engage can be very useful to both teachers and teacher education programs.
}

responding productively to constraints and opportunities of real teaching situations [21,27-30,34,48,49]. For references addressing this matter in physics teacher preparation, see Refs. [7,42,45,50,51].

- Shaping a community.-Learning to teach means becoming a part of the community of teachers and happens in a community of other students, teachers, and teacher educators. Collaboration and support are the pillars of successful integration into the cultural practices of a community. The programs should therefore aim to shape teaching and learning communities that work towards and perpetuate a shared vision of good teaching and integrate students into such communities [21,27-29]. Windschitl et al. [52] emphasize the role that tools can play, when used collaboratively, in the induction of novice teachers. Furthermore, there is extensive literature on the use of the collaborative study of student work, mostly at the in-service stage. (Critical Friends Groups [52,53] and Looking Together at Student Work [54] are examples of such approaches.) References that address the role and importance of the community in becoming a physicist and a physics teacher include Refs. [7,41,42,55,56].

- Preparing for life-long learning.-The programs should aim to develop teachers that reflect on their practice, are prepared and willing to be life-long learners, and take an inquiry stance towards their teaching-characteristics of great importance in the fast-changing world of today [21,27-29].

The chapters in Ref. [34] address several of these points. Similarly, in his review of teacher education in physics, Meltzer writes [45] (p. 11)

"[C]ertain themes have appeared in the literature with great regularity. Evidence has accumulated regarding the broad effectiveness of certain program features and types of instructional methods. The major lesson to be learned from the accumulated international experience in physics teacher education is that a specific variety of program characteristics, when well integrated, together offer the best prospects for improving the effectiveness of prospective and practicing physics teachers. This improved effectiveness, in turn, should increase teachers' ability to help their students learn physics. These program characteristics include the following:

(1) a prolonged and intensive focus on active-learning, guided-inquiry instruction; (2) use of research-based, physics-specific pedagogy, coupled with thorough study and practice of that pedagogy by prospective teachers; and (3) extensive early teaching experiences guided by physics education specialists."

The recommendations of the T-TEP Report [3], which encapsulated the findings of the Task Force on Teacher Education in Physics, reflect these program characteristics.

In both the general and physics-specific teacher education literature, therefore, there is emphasis on providing 
prolonged, thorough, and extensive experience to prospective teachers. This experience shapes and, reflexively, is shaped by productive knowledge, skills, and dispositions.

\section{TEACHING AS A HABITUAL ACTIVITY}

In addition to the above-discussed and widely agreedupon characteristics of effective teacher preparation, we propose that another important, yet often underconsidered component of teacher preparation is the formation of habits. This echoes the perspective taken by John Dewey, when he considered habits as playing a central role in human thought and behavior [57].

\section{A. Habits: Dispositions, knowledge, and skills}

In the dictionary [58], a habit is defined as "a settled or regular tendency or practice, especially one that is hard to give up." This agrees with the everyday sense of habits being solidified ways of thinking and acting that are resistant to change. However, an additional subdefinition from psychology says that a habit is "an automatic reaction to a specific situation." We take the latter definition as the starting point of our discussion. The idea of habits being dependent on particular situations also aligns well with John Dewey's discussion of habits being context sensitive [57].

Our aim is to allow teacher educators to consider habit formation as it relates to more established ways of conceptualizing teacher preparation. In line with our aim, we propose, for the purpose of this paper, that a teacher's habits have their roots in her dispositions, knowledge, and skills - three established concepts in the teacher education literature (general $[59,60]$ and physics specific [56]). We in turn explain in more detail what we mean by each of these words and how each of them can be connected to a teacher's habits.

\section{Dispositions}

A "disposition" is defined as "a person's inherent qualities of mind and character" [58]. Such definition does not fit our meaning of this word in a teacher preparation context. We define a disposition as a strong (often subconscious) belief or attitude related to some aspect of teaching, that in concert with other factors, shape a teacher's behavior and thought.

Imagine a PST who believes deeply that physics is a difficult subject and only a few selected students can learn it. How does this belief affect the choices that this teacher will make in the classroom? An example here would be assessment. If the teacher believes that only the brightest students can master physics, then the role of assessment may be interpreted as a one-time grading filter that distinguishes more and less able students. If on the contrary, the teacher believes that all students can learn physics but need different amount of time and effort, then this teacher will set up a system where a student can continuously improve her work and consequently, improve her grades. As we can see from this example, the difference in the belief of what constitutes student ability to learn leads to huge differences in classroom instruction.

Taking PSTs' dispositions into account, learning to teach begins long before PSTs enter teacher preparation programs. Out of all kinds of professional learning, learning to teach is special in the sense that all future teachers have, in the course of their own education, observed other teachers working for thousands of hours before they themselves started formal teacher training. This so-called "apprenticeship by observation" [61] is usually considered to be more potent than formal teacher education $[4,21,27,29,62]$. The robustness of PSTs' existing dispositions pose a challenge to teacher educators since they play an important role in how teachers perceive new information, frame situations and act in practice $[25,63]$. Therefore, teacher educators should not ignore the central role of PSTs' attitudes and beliefs in the process of learning to teach [64].

It is not difficult to see why dispositions play a central role in the formation, cementing and sustaining of teachers' habits. While Dewey [57] used the terms dispositions and habits interchangeably, and Nelsen [65] proposes that dispositions are in fact composed of clusters of related habits, we suggest, for the purpose of our argument, that dispositions serve as an intellectual and affective context in which habits develop.

\section{Knowledge}

Much like dispositions, knowledge affects what one notices, what one considers as being relevant, and how one decides to act. While a teacher's knowledge has different sources, in the context of preservice teacher preparation, knowledge is usually associated with the content of different courses that PSTs take in the process of education (e.g., subject content knowledge, knowledge about students and learning, content knowledge for teaching particular subjects). Much has been written about the nature of teacher knowledge and the differences between content knowledge, pedagogical content knowledge, and content knowledge for teaching a particular subject. The interested reader can find relevant information in Refs. [5,66-68]. Much like dispositions, we see a teacher's knowledge as the intellectual context for the shaping of a teacher's habits.

\section{Skills}

For our purposes, a skill is a precompiled procedure that one deploys automatically without consciously thinking about it. We break down these skills into mental, technical, and emotional skills.

Mental skills relate to operations that a teacher needs to execute on a regular basis and in the spur of the moment. For example, reflecting critically on one's lesson is a skill that a teacher needs to use after each lesson, while changing the flow of a lesson based on a student comment is a skill 
that is executed at the "right" moment. It is thus not difficult to see how the use of such a skill is strongly dependent on one's dispositions and knowledge and how it is intimately connected with a teacher's habits.

Technical skills relate to the ability to operate and fix equipment and to operate modern technology. Technical skills are especially important at smaller schools where there are no lab assistants or in schools where resources for equipment are scarce [69], for example.

Emotional skills relate to the ability to keep cool no matter what happens in the classroom and the ability to put children's welfare and learning first.

Although there seems to be a thin line between a skill and a habit as both are automatic and often subconscious, we treat skills separately because being skilled in something does not necessarily mean doing it habitually. Skills can therefore be seen as resources that are activated and drawn upon in the process of habit development and enactment.

We must note that habits, as we understand them, do not unidirectionally flow out of one's dispositions, knowledge, and skills, but also feedback and impact the very intellectual context from which they emerge. This, for example, means that one can form a habit of reading teaching literature, which in turn influences the intellectual context in which habits develop.

\section{B. Role of habits in teaching and teacher preparation}

Teachers unavoidably develop habits with practical experience and under the influence of knowledge and belief structures that in many ways condition the responses of teachers in their practical work. This way, many of the tasks of teaching become more automated with time, which also allows teachers to devote more of their conscious attention to other tasks.

The habits that teachers develop when they enter teaching for the first time will often be shaped by the pressure and demands of a very dynamic environment and may as a result be directed towards teacher "survival" instead of student learning. It is therefore very important that the teacher "brings with her" a set of habits that will allow her to get a grasp of the situation and actively steer her practice in a direction that will lead to student learning, as well as her own advancement of teaching, instead of merely "surviving".

One way of seeing habits is therefore as teacher's tools. However, as Dewey points out, they are more than just that. They are tools that themselves carry some degree of agency - they also direct one's thoughts and actions [57].

While a good teacher is reflective about her practice [70], teaching to a large extent involves routine decision making and behavior [71,72]. At first sight, the idea of automated behavior may seem at odds with a teacher who responds to the demands of a particular context. There are different ways of tackling this apparent discontinuity in logic (e.g., Refs. [22,73]). What these approaches have in common with the Deweyan conceptualization of habits is that they allow for spontaneous behavior to be responsive to cues from the surrounding context.

Thus, the habits we have in mind are not meant to be enacted as inflexible, mindless scripts for teaching, but rather as an initial toolkit or a support structure of strategies for automated behavior that will allow a new teacher to successfully start practicing reformed teaching and help her avoid picking up unproductive habits under the pressure of real teaching environments, or reverting to the "old ways," learned through the apprenticeship of observation, which are in most cases less supportive of student learning. ${ }^{3}$

\section{Development of habits in preservice teachers}

Looking through the lens of habits, one of the goals of a teacher preparation program should be to give attention to the development of productive habits and phasing out (or replacing) unproductive ones that PSTs may bring with them into the program.

Some habits will be productive for all teachers, some may be particularly important for teachers in specific disciplines, and some will only be present in specific disciplines, such as physics. We provide an illustrative list of habits we consider productive for physics teachers in the next section.

For Dewey, context plays an essential role in habit formation and enactment [57]. For example, a teacher may habitually employ humor during teaching in their mother tongue, but due to the lack of confidence, does not have the same habit when teaching in their second language. Context dependency also means that habits are mutable, not completely resistant to change [65]. They emerge in context and depend on context: physical, social, and intellectual. This idea suggests a possible mechanism for the changing of habits. Dewey claims that "[w]e cannot change habit directly: that notion is magic. But we can change it indirectly by modifying conditions, by an intelligent selecting and weighing of the objects which engage attention and which influence the fulfillment of desires" [57] (p. 20).

If one of the goals of a teacher preparation program is to affect PSTs' habits, programs need to set up conditions that will allow for the emergence of productive and phasing out of unproductive habits. In order for prospective teachers to acquire new habits, conditions need to be set up in which

\footnotetext{
${ }^{3}$ The idea of permanently cementing habits into PSTs is essentially unfeasible (and probably of questionable desirability), unless conditions remain the same. Teachers therefore need to be prepared to enact habits in flexible and context-responsive ways and critically reflect on them throughout their career. Nelsen [65] expresses a similar idea using the idea of "intelligent dispositions."
} 
their existing but unproductive habits will not function anymore and in which new habits will emerge [65].

This is not an easy task. As Dewey himself puts it, the changing of habits can hardly be achieved by merely countering old habits. By doing so, we tend to invoke the conditions that set in motion the old habit. New habits need new conditions, different from those that invoke and cement the old habits.

This means that if a program takes habit formation in PSTs seriously, it should aim to provide PSTs with a suitable physical, social, and intellectual environment-a community of practice $[12,74]$ - that sets up, sustains, and perpetuates conditions for the formation of productive habits. This means setting up the social and physical conditions that will support the formation of productive habits, which will serve new teachers well when they leave the program.

In the next section, we will present an illustrative selection of habits that we see as important for physics teachers that will teach in accordance with NGSS.

\section{PRODUCTIVE PHYSICS TEACHER HABITS INFORMED BY NEW STANDARDS}

In this section, we describe the habits that we think are important to be formed before a newly minted physics teacher goes out into the world. These habits should help the teacher create a classroom consistent with the Next Generation Science Standards (NGSS), where all students are engaged in the exploration of disciplinary core ideas by practicing science and building their knowledge on cross-cutting concepts [1]. This new 21st century learning environment that needs to be created demands different habits compared to the habits of a teacher in the 20th century. Not only do the recommendations of the NGSS call for different teaching but everything that we know about brain structure and function, conditions for learning, and specifically how people learn physics - which we did not know 20-30 years ago-makes it necessary to reconceptualize our teaching of physics and other subjects and consequently, the habits that a physics teacher (or any other teacher for that matter) needs to develop.

In Sec. IV A we outline productive habits of mind, of practice, of maintenance, and of leadership, both physics related and physics teaching related, which a physics teacher education needs to inculcate in PSTs. In Sec. IV B, we outline the knowledge, skills, and dispositions that undergird such habits. We also include some habits that are not exclusively physics specific but are crucial for a physics teacher to develop. It is important to note that some of those habits are useful for all teachers; some others, for all science teachers. However, for those other teachers, there might be other useful habits that we are not mentioning here. We do not claim to produce a final list of habits, we aim to provide examples of the habits that we consider critical.

\section{A. Habits of mind, practice, and maintenance and improvement}

Below, we outline the specific habits of mind and habits of practice that need to be developed by a prospective physics teacher. Consequently, when one designs or reforms a teacher preparation program, it is good to keep in mind the development of the following habits. Although we are using physics as the domain of investigation, if one were running a program that prepares teachers of multiple disciplines, one might think how each of those habits applies to each of those disciplines. Some of the habits are more important for physics teachers, than say, biology teachers, but overall, a teacher of any (every) discipline needs to have those three types of habits developed in relation to the discipline one teaches.

Habits of mind.- These are the examples of habits of thinking like a physicist and thinking like a physics teacher in the new environment. By physics habits of mind we mean spontaneous thinking of and noticing the application of physics ideas in the surrounding world and in the "playground" of other disciplines, such as mathematics. By physics teacher habits of mind we mean spontaneous thinking and attending to student physics-related reasoning, questioning, and development.

Habits of practice.-These include (a) the habits that involve spontaneous decisions during lesson planning and (b) the habits, which enacted in the classroom, lead to student learning. The habits of practice are therefore intertwined with the habits of mind and cannot be separated definitively.

Finally, habits of maintenance and improvement are the habits that involve continuous learning on the part of the teacher as an individual and as a member of the community, as she organizes her professional life to give priority to maintaining the community, actively sharing new findings, and using the findings of other teachers.

Selected physics habits of mind.-The list below was compiled based on the history of physics, physics education literature, and observations of the work of physicists in real time [75-78]. We recognize that the list is not exhaustive but hope that it gives the reader a flavor of what we have in mind.

- Noticing application of physics laws in the surrounding world (for example, thinking of static friction when walking, noticing diffraction pattern on eye lashes when squinting, etc.).

- Approaching problem solving as a physicist (napkin calculations, drawing a sketch before solving any problem, being able to do an order of magnitude estimation, being able to do a long calculation without a calculator just using powers of 10 , etc.) $[79,80]$.

- Treating physics as a process, not a set of rules or a collection of information, specifically seeking to understand how physics ideas have emerged in specific historical contexts, how they are connected with 
progenitor ideas, and how they have given rise to subsequent ideas [81,82]. This habit of mind protects against naive hero worship by providing more nuanced understanding of the ecology of physics concepts as invented intellectual entities. Examples of such epistemological habits of mind include inductive (experiment-based) and "spherical cow" reasoning, analogical reasoning, establishing causality, questioning claims, quickly assessing coherence of suggested ideas with the rest of the physics body of knowledge, and being able to spontaneously think of an experiment to test an idea when it is proposed (hypothetico-deductive reasoning).

- Using mathematics in a physics-specific way [83-86]. Specifically, mathematics plays a different role in physics compared to other sciences. Physics is much less statistics oriented than biology and more oriented towards mathematical modeling and internal consistency of multiple representations [80] than chemistry.

Although all the above habits are important for any science teacher, the nature of each differs with the discipline. For instance, as we said above, mathematical reasoning in biology is different from mathematical reasoning used in physics, however, teaching a discipline as a process and not as a set of rules applies to any science subject.

Selected physics teacher habits of mind and practice.The following nonexhaustive list is compiled based on the documents governing science education (Framework for K-12 Science Education and NGSS) [1,2], physics education literature, science education literature, and general literature on how people learn [4,12,18,74-77,81,87-97].

- When helping students learn, starting by helping them connect new ideas to their existing ideas recognizing that student ideas about a specific set of physical phenomena have been developed over years of organizing, perhaps uncritically, a rich set of experiences, full of complexity and messiness. School physics, on the other hand, is often sanitized and deals with idealized contexts. In the same way that to Greek two-year olds their language is not "Greek to them," students can be extremely successful in predicting, with almost zero conscious analysis, where a tossed ball will land or how to place boxes of different sizes on each other so that they will not tip over $[88,98]$.

- Attending to students' thinking specifically regarding physical mechanism, interaction, conservation, constraint, and processes of change and transformation $[1,88,99,100]$. Seeking to establish a step-by-step causal chain to understand a particular phenomenon or to search for a mechanism (or a set of mechanisms) instead of just describing the phenomena by collecting and analyzing data.

- Encouraging students to test their ideas experimentally instead of waiting for validation from authority.
For example, in physics, it is often easy and highly productive to say, "Go ahead and try it; set it up (bulbs, cart, magnet) and see what happens." In chemistry, that may not be true, and in biology, it is very unlikely to be true; that is, you would need to make a different "spontaneous decision" $[1,88]$.

- Listening to student conversations, comments, and questions related to physics (both content and practice) and altering, revising, improvising planned instruction to build on students' ideas [98,101,102].

- Reflecting on the role that language plays in student learning and making conscious choices of words and grammatical construction when talking about physics so as not to create confusion (for example, knowing that "heat" means different things in physics and in the daily life of students; or choosing the appropriate time to differentiate gravitational potential energy in an object from the energy of a system of gravitating objects, etc.) [89,103].

- Treating all students as capable of learning physics and contributing to the generation of physics knowledge (as opposed to treating learning physics as a weed-out competition) [104,105].

- Being aware of the "surroundings" (nature, current events, such as breakthroughs in science or socioscientific issues, such as climate change, etc.) as a source of learning physics (for example, watching waves going over a rock in the sea and taking a video to use in the lesson on diffraction) by building on the inherent ease of experimentation that physics affords; habitually thinking of how to use an everyday simple phenomenon, video, etc. to help students notice, wonder about, and learn something (for example, stumbling upon a video on YouTube and immediately incorporating it in the lesson the following day); dumpster diving (not passing by something in a dumpster that can be used for helping students learn physics) through a conviction that cheap, readilyavailable materials can serve as the basis of a good physics lesson.

It is unlikely that these habits will be developed efficiently without deep connections to physics as an experimental science and to results of physics education research, which provide PSTs with tools that help build these habits. For example, what are productive questions to ask students who are learning about electric current to make sure that they understand the difference between series and parallel connections? How do you make sure that the Wimshurst generator that the school owns lasts for a long time?

Finally, habits of maintenance and improvement need to be developed. For example, being a member of a professional organization such as AAPT or AMTA and habitually reading The Physics Teacher is one of those habits. Being a member of the local section of the AAPT, attending 
workshops led by local teachers, or being connected to the physics department of a university are additional examples of such habits.

An important subset of these habits consists of habits of leadership. Habits of leadership involve spontaneous steps to engage other teachers in thinking about student learning and showing examples of how to do it. For example, having a discussion about the implementation of NGSS in the teachers' lounge during lunchtime, sharing new ideas learned in a workshop with other teachers, etc.

We have operationalized the above habits in the context of physics teacher education. As Meltzer puts it, "The[se habits] should be integrally linked to the emotions experienced by physicists in wondering about, exploring, and discovering underlying coherence in the world around us; else they may become mere boring drudgery, analogous to adding columns of numbers. Teaching habits should be linked to effective engagement in joyful communication of new ideas and abilities to interested students; the alternative is obvious, and depressing to contemplate" [106].

\section{B. Dispositions, knowledge, and skills needed for the development of the selected habits}

In this subsection we describe dispositions, knowledge, and skills that form the foundation for the habits of mind and practice described above and follow from our assumptions described in Sec. III. B. We start with dispositions as they determine what knowledge and what skills the PSTs "choose" to appropriate during the program [25,62,64,71,107-109].

\section{Dispositions}

Below we list the most important dispositions that we consider crucial for a successful physics teacher. Although some of the listed dispositions may be desirable for teachers in subjects other than physics, their impact on teaching physics is particularly critical because of the unique opportunities that physics affords for the development of students' critical thinking skills and scientific competencies, which themselves arise from the nature of physics knowledge and the process of the development of this knowledge.

- Learning of physics is doing physics. Just as physics is a specific process of inquiry into nature and not a static set of rules to be mastered, learning physics is a process that should reflect the nature of physics as both an experimental and a theoretical science. ${ }^{4}$ Learning of physics involves learning of the process of physics as much as its final outcome [1,2,81,88,90,91].

- Learning of physics is a social co-construction of knowledge through experimentation and reasoning that leads to changes in the brain of the learner

\footnotetext{
${ }^{4}$ The recent national attention to computational literacy lends itself to an additional focus of physics instruction, namely, physics as a computational science.
}

[92]. The roles of the teacher in this process is to guide, provide informed feedback, and support [93].

- Learning is a complex process, which cannot be reduced to the following dichotomy: student either got it or did not get it. The a priori position of the teacher should be that all students are capable of learning physics, but every person learns at their own pace. Research shows that teacher expectations can influence student achievement [110].

- Learning of physics does not happen in a vacuumeverything that happens in the classroom is affected by a student's experience, language, and environment [20,89,94].

- Intrinsic motivation is to be treated as the crucial attendant to learning. In physics, student motivation comes from noticing that one is becoming more successful, from being able to apply physics knowledge to relevant everyday experiences, and from experiencing the inherent intellectual excitement of physics [95,111-113].

- All decisions in the classroom are to be guided by the "learning compass." If a certain decision is likely to lead to more learning and better well being of students, it is a productive decision; if it is likely to impede learning or to reduce the quality of student wellbeing, it is counterproductive. These decisions are often triggered by students' comments or questions that require the teacher to alter the existing lesson plan. The readiness to change the plan using the above compass is the disposition of a reformed teacher [20].

- A teacher is always a learner and aspires to become an expert learner.

The dispositions described above might serve as a filter for the knowledge that a PST appropriates during the program. The above dispositions are to be developed throughout the program. Note that although the dispositions might seem generic, their instantiation is intrinsically physics specific. For example, a common view of physicists in society is that physics is only for very smart people and thus not everyone can learn physics. Cultivating the disposition that all students can learn physics and developing habits of practice built on this disposition will dramatically change the number of students successful in physics and the image of a physicist in the society.

\section{Knowledge}

Here for brevity we discuss what knowledge is needed for the development of selected important habits. We choose knowledge needed to develop some physics specific, some science specific, and some general habits. However, all of those need to be developed in the context of the discipline.

- Habit (physics specific): Approaching problem solving as a physicist.-Physicists do not solve problems by searching for the right formula to plug in the givens (the 
novice approach) [80]. Instead they draw a picture of the situation, think of it conceptually first without searching for equations, appeal to grand principles rather than superficial features, solve equations symbolically before plugging in any numbers, and finally evaluate the solution. Traditionally, the types of "problems" (more appropriately, exercises) that students encounter in general physics courses tend to be short, quick applications of one or two formulas [114,115]. At that stage of study, many of the students do not know that they will become physics teachers. Later, when they start working towards their physics education degree, they are usually enrolled in upper division physics courses that do not involve problem solving that is as relevant to their vocation. This leaves PSTs at the level of novices with respect to the high school level physics problems. Thus, in the teacher preparation program special attention should be given to the procedural aspect of problem solving of typical and atypical introductory physics problems so the PSTs develop expertlike problem solving strategies [76,77].

- Habit (physics specific): Using mathematics in a physics-specific way.-To develop this habit the PSTs need deep conceptual and not just procedural understanding of the nature of physics equations and the difference between operational definitions (density is equal to the mass divided by volume) and cause effect relationships (acceleration is equal to the sum of the forces divided by mass); functional understanding of proportional reasoning, the difference between the meanings of mathematical operations in mathematics (where multiplication can be always reduced to addition) and in physics (where it often cannot be, for example $p=m v$ ). The work of Sherin, Redish and colleagues, Brahmia, Kanim, and many others can help physics teacher educators develop appropriate habits of mind [83,85,86,96,116-118].

- Habit (general): Helping students connect new ideas to their existing ideas and applying them to real-world phenomena.-Here the knowledge of students' ideas is invaluable. It has been documented in the literature and PSTs definitely need to be familiar with this work (see Refs. [119,120] for exhaustive lists of references). However, this knowledge by itself is not sufficient. Knowing student ideas should lead to the knowledge of how to anticipate student thinking around these physics ideas, how to promote their interest, how to monitor student development (what types of questions to ask in a specific situation, e.g., what do you mean by the word "force"?), what types of questions are unlikely to yield productive insights into student thinking in a specific context (What is energy?), how to interpret and act on student thinking (for instance, when a student says that when a ball thrown upward slows down to a stop it is because the force given to it by the hand runs out, what might the student's cognitive or experiential need be? [89]). In other words, a reform-oriented physics teacher needs to know how to take student ideas and help the students move forward in a way that is consistent with physics practice. This knowledge rests on the deep knowledge of physics as a process and deep knowledge of PER as a field of study of student learning of physics.

- Habit (general): Preparing every lesson carefully attending to three components: goals, assessment, and activities.-To develop this habit the PSTs need generic knowledge of instructional planning (units and lessons), but they also need to know what this means for specific lessons. Therefore, they need to be familiar with the documents discussing the goals and assessment of physics instruction (e.g., NGSS) and with the resources for physics activities and assessments (for example, Refs. [121-128]). In addition, the PSTs should have strong knowledge of curriculum as a map that allows students to build new ideas on something that they already know. For example, PSTs need to be able to explain why one needs to be familiar with the kinetic molecular theory to understand sound waves and why one needs to understand the concept of a system to learn energy. This is especially relevant given research results that show that the quality of new teachers is determined by the amount of experience they have with day-by-day implementation of instructional units in their preparation programs [129].

- Habit (science specific): Language awareness.-A great deal of knowledge is needed here. PSTs need to develop an understanding of ways in which learners use analogical and metaphorical language and recognize the instructional affordances of the use (or misuse) of metaphorical language by students. PSTs also need to understand student difficulties with specific terms (force, flux, heat, weight) that have a different meaning in everyday life compared to physics, and grammatical constructions that change the physics meaning of a concept (e.g., an object in a potential well) (see Refs. [89,103,130]).

- Habit (science specific): Being aware of the surroundings (nature, current events or societal issues, etc.) as a source of learning physics.-To develop this habit PSTs need deep knowledge of physics, knowledge of curriculum goals and knowledge of equipment.

\section{Skills}

In Sec. III we defined what we mean by skills and we described different kinds of skills that a physics teacher needs to develop. Although there seems to be a thin line between a skill and a habit as both are automatic and often subconscious we treat skills separately because being skilled in something does not necessarily mean doing it habitually. For example, we are all skilled in drinking water 
but not all of us have a habit of drinking the requisite number of glasses a day.

Examples of mental skills include interpreting skillfully what students say using physics language, expressing a complex physics idea in simple words and/or without mathematics; doing power of ten estimations in one's head (including remembering the order of magnitude of important physical constants); fluently using physics-related mathematical skills such as ranking possible effects according to their size or proportional reasoning.

Examples of technical skills include using all traditional equipment for physics curriculum; building and troubleshooting electric circuits, soldering, repairing simple equipment, maintaining equipment; having deep knowledge of document authoring and spreadsheet applications (like mail merges, graphing, etc.); using educational technology for communication with students; using physics technology for data collection and analysis; choosing and purchasing quality equipment efficiently.

Examples of emotional skills include empathetic appreciation of the challenges that a novice learner faces when confronted with difficult ideas or a parent faces when confronted with an assessment of learning challenges of the child; interpreting adolescent student behavior not as an immediate reflection of the teacher's popularity but as a form of expression of the student's internal state; being able to think and multitask under stress.

\section{THREE MECHANISMS FOR PRODUCTIVE HABIT FORMATION}

In this section we discuss the mechanisms through which physics teacher preparation programs can help future physics teachers develop the knowledge, skills, dispositions described above, and the conditions that should be met to use those for successful habit development. Starting from the perspective that learners of all kinds bring a rich fund of ideas based on years and years of active and passive sense making, PSTs bring to the program their own views of what constitutes physics learning and good teaching. Unfortunately, often these views are based on the experience with traditional instruction [131]. Thus, if we wish that our future teachers develop the habits described above, we propose that a program needs to integrate three components: (a) extensive apprenticeship-based clinical practice, (b) in-depth coursework on the learning and teaching of high school physics, and (c) the care and feeding of a rich community of practice [74]. ${ }^{5}$ Our recommendations are simultaneously general and physics specific.

\footnotetext{
${ }^{5}$ To be sure, there need to be additional components to the program that attend to important general aspects of teaching and learning, as well as to treatment of the student as a developing human being, to understanding contextual characteristics of schools and the teaching profession, to gaining familiarity with state requirements, etc.
}

\section{A. Apprenticeship-based clinical practice}

Any apprenticeship begins with students observing a master performing the craft. In our case, observing reformed physics teaching and being in the role of a student in this environment is crucial. PSTs need to have images of effective physics learning and teaching before they can start practicing such teaching themselves. Thus the PST first needs to observe reformed physics instruction and then slowly start participating in it serving as an apprentice to the master teachers, with the master teachers providing scaffolding for the PST's tasks [42], guidance at the microlevel of their implementation and substantive feedback in real time [51,56,132]. This construal of clinical practice takes on urgent importance in the context of the national landscape of physics teacher education, according to which the majority of physics teachers (as opposed to biology teachers, for instance) are (a) the only such teachers in their schools and (b) do not have a physics major or minor. Placing PSTs in state-mandated teaching practica is treated often, therefore, as a matter of logistical matchmaking rather than intentional modeling of the vision of the physics teacher education program. One way to fix this conundrum is to maintain close contact with program graduates and continuously interact with them professionally so they grow into the master teachers for new PSTs [42].

Since habits take a long time to develop and become cemented [133], it stands to reason that the program needs to provide early and multiple opportunities for reflective practice conducted in service of habit development. We envision a progression of such clinical practice: from observation, reflection and analysis of specific aspects of effective teaching modeled by master physics teacher(s) (for example, a teacher in residence [132]) to opportunities provided to the apprentices to try out short, discrete tasks of teaching [42] in the context of a reform-centered physics classroom (university or K-12) with subsequent reflection, to increasingly more formal teaching occasions all the way through to the ultimate relinquishing of scaffolds at the very end of student teaching, as the teacher candidate has shown repeated evidence that effective habits have been appropriated. All these experiences come with an expectation of repeated attempts by the apprentice, performed in the presence of the community of the master teacher and other apprentices, and the incorporation of the immediate feedback of the master teacher. It is crucial that all "masters" participating in the process explicitly share the same vision for good physics teaching and the same dispositions as described above. (For examples of structuring clinical practice using the community-based apprenticeship, see Ref. [34].)

In learning how to teach physics the crucial element is participating in designing, teaching, analyzing, and reflecting on instruction that places emphasis on students' scientific inquiry. Many teachers have not experienced 
this kind of instruction and do not practice it, thus the placement of PSTs in the classrooms of those who indeed practice effective inquiry-based instruction is a challenge. Consequently, cooperating teachers need to be skilled in using physics experiments as a means of helping students to construct, test, and apply knowledge. In such classrooms PSTs can develop a repertoire of productive experiments, become familiar with common equipment used in schools and have an opportunity to learn how to repair equipment and how to invent new hands-on ways to learn physics. A related challenge is the partnership of PTE programs with a teacher in whose classroom physics learning does not consist of solving mathematical word problems alone but the classroom also serves as an environment in which students have multiple opportunities to describe real world phenomena through multiple representations.

According to our model then, the typical generic classroom observations that are intended to familiarize the PST with school contexts, followed by the standard student teaching experience, understood here as the placement of an individual teacher candidate in an arbitrary collaborating teacher's classroom to fulfill a state statute that has a specified one-size-fits-all duration (and that often-but not always-is held in parallel with enrollment in a general science methods course that emphasizes the development, implementation, and assessment of a single lesson in great detail or at most a small unit), although valuable, are woefully inadequate in helping novices to develop a toolbox of thoughtful habits and a beginning curricular repertoire for the whole year. In our experience, it takes more than a year of this closely supervised apprenticeship-based practice that allows a personalized schedule of slow removal of scaffolding, for a teacher to be able to start the first day of school with confidence in her habits and a plan for the first, second, third, and $N$ th day of the first year of teaching. In addition to mastering the content they need time mastering the equipment-using, fixing, etc.

\section{B. Coursework on the learning and teaching of physics}

A quick read through Sec. III illustrates that the specialized knowledge required to teach physics is not the content focus of even the best reformed physics courses. Personal experience in content courses that model researchbased instructional practices may be very valuable in improving students' conceptual understanding and problem solving, and in certain cases, may even improve students' physics expectations [131]. But having had good teaching modeled does not guarantee that the PSTs in a physics course will be able to then lead others to learn effectively. Specialized courses in physics learning and teaching are required [40]. As a matter of fact, a sequence of such courses is required because habits are unlikely to develop as a result of participation in a single course. (For examples of such courses, see Refs. [7,134-137].)
The emphasis of these specialized courses is to help PSTs understand and reflect on the ecology of physics ideas and the evidentiary and reasoning chains that have led us to believe what we believe (specifically, experimental testing of explanations, models, hypotheses), learn the fine structure of student ideas that they can anticipate in the topics they will be teaching, learn topicspecific questions or tasks that research has shown to be promising in opening up student discourse, learn the affordances and limitations of different technical representations so that they can recognize physics productivity in students' own spontaneous representations, learn how to assess what is of value to the physics community, etc. [66]. Recent research in teacher knowledge shows that it is not subject but topic specific [66], thus the coursework should provide the PSTs with the opportunity to examine every (or as many as possible) physics topic from the teaching point of view, not just have an example from one topic. In this sense, the courses envisioned here work hand in hand with the clinical experiences, with a temporal sequencing of courses or practica that front loads what is absolutely needed and no more, and then introduces additional pieces on a need-to-know basis, over a period of time that is sufficiently long for PSTs to integrate knowledge with practice through the exercise of productive habits.

An important element of such courses should be microteaching. Microteaching is a technique used in teacher preparation, whereby PSTs teach a K-12 lesson to their peers, who act as students. Such practice can be extremely useful. PSTs learn to plan a lesson, to interact with students, and to reflect on the lesson after its implementation [42]. This structure also allows multiple opportunities for the mentor (i.e., the course instructor) to provide formative feedback to the PST, and to give the PST an opportunity to revise a particular moment of the lesson and "replay" it. Microteaching is similar to using a flight simulator in pilot training. For preservice physics teachers microteaching is especially useful (in addition to the general benefits it provides teachers of all subjects) as they have an opportunity to interact with equipment, see the constraints that available equipment puts on their plans and borrow or repair it if needed.

\section{Physics teaching community of practice}

A rich and diverse community of practice comprised of the master teacher(s), program faculty and staffincluding university supervisors, the PSTs, undergraduate and graduate students interested in teaching and learning, and in-service teachers (especially program graduates) serves multiple goals of the program $[42,56,132,138,139]$. The community continues to serve as a complex of positive feedback loops as it reinforces habits and common values, as a context for feedback from the field that informs changes to the program, as a social network 
that increases chances that a teacher candidate will be placed in an instructional environment that embodies the program's vision, and, most importantly for the in-service teachers in the group, as a safe environment in which they can share dilemmas of practice and stay culturally connected to the physics enterprise that inspired them in the first place. The solitary nature of physics teaching and the availability of other career choices to holders of a physics degree are peculiarities of physics teaching that urgently call for special attention to this aspect of a physics teacher education program. To the best of our knowledge, there exist only a handful of programs in the U.S. that have engendered this kind of community. Such programs are described in Refs. [42,93,140-142].

It is in the interwoven nature of the three components (apprenticeship-based clinical practice, coursework on the learning and teaching of physics, and physics teaching community of practice) that the knowledge, skills, dispositions, and the related habits are developed. In addition, a strong sense of identity and enthusiasm about teaching physics is cemented and culturally propagated.

\section{IMPLICATIONS AND RESEARCH AGENDAS}

A major goal of this paper has been to make the case for the importance of organizing physics teacher education programs around the development of productive habits by future teachers. Taking this organizing principle to its logical conclusion, a testable implication emerges: physics teacher education programs that do not provide adequate opportunities for prospective teachers to develop the requisite habits are unlikely to produce novice teachers who can handle the demands of the classroom in ways that are consistent with the vision of the NGSS.

Several research questions emerge from this premise. What are some of the most significant habits for physics teachers to develop, and toward which desired outcome?
How will we measure the degree to which the knowledge, skills, and dispositions underlying these habits are being attained? How may habit development be operationalized and measured? What are some efficient ways in which programs can provide opportunities for students to develop these habits? What constitutes an adequate number of opportunities to develop these habits?

It is our sincere hope that the PER community will pursue some of these and other related research questions, as well as engage first in the prerequisite hard work of further defining operationally, refining, and differentiating among still-slippery terms such as knowledge, skills, dispositions, habits, etc. There is a national and international need to bring to bear on physics teacher education the PER perspectives, tools, values, and habits that have contributed so much to reforming physics instruction.

Let us be clear that we do not espouse a specific type of physics teacher education program. Rather, we invite the community to engage with the substance of our major claim, namely, that ensuring the development of productive habits is an important goal of physics teacher education and, consequently, that an intentional enumeration of the specific central habits that are valued by a given local instantiation should guide the very design of the corresponding PTE program.

\section{ACKNOWLEDGMENTS}

We are indebted to the numerous anonymous reviewers and David Meltzer for their numerous suggestions that led to the present version of this paper. S. V. is grateful to the Physics Education Research Group at Seattle Pacific University for innumerable conversations that helped in part to shape his views on the professional preparation of teachers.
[1] NGSS Lead States, Next Generation Science Standards: For States, By States (The National Academies Press, Washington, DC, 2013).

[2] A Framework for K-12 Science Education: Practices, Crosscutting Concepts, and Core Ideas, edited by $\mathrm{H}$. Quinn, H. Schweingruber, and T. Keller (The National Academies Press, Washington, DC, 2012).

[3] Transforming the Preparation of Physics Teachers: A Call to Action. A Report by the Task Force on Teacher Education in Physics (T-TEP), edited by D. E. Meltzer, M. Plisch, and S. Vokos (American Physical Society, College Park, MD, 2012).

[4] S. Feiman-Nemser and J. Remillard, Perspectives on learning to teach, in The Teacher Educator's Handbook:
Building a Knowledge Base for the Preparation of Teachers, edited by F. B. Murray, 1st ed. (Jossey-Bass, San Francisco, 1996), pp. 63-91.

[5] D. H. Gitomer and R. C. Zisk, Knowing what teachers know, Rev. Res. Educ. 39, 1 (2015).

[6] R. M. Schneider and K. Plasman, Science teacher learning progressions: A review of science teachers' pedagogical content knowledge development, Rev. Educ. Res. 81, 530 (2011).

[7] E. Etkina, Pedagogical content knowledge and preparation of high school physics teachers, Phys. Rev. ST Phys. Educ. Res. 6, 020110 (2010).

[8] L. C. McDermott, P. S. Shaffer, P. R. L. Heron, M. R. Stetzer, and D. L. Messina, Preparation in the knowledge 
and practices of physics and physics teaching, in Recruiting and Educating Future Physics Teachers: Case Studies and Effective Practices, edited by C. Sandifer and E. Brewe (American Physical Society, College Park, MD, 2015), pp. 165-186.

[9] D. L. Ball, M. H. Thames, and G. Phelps, Content knowledge for teaching: What makes it special?, J. Teach. Educ. 59, 389 (2008).

[10] A. Reynolds, What is competent beginning teaching? A review of the literature, Rev. Educ. Res. 62, 1 (1992).

[11] A. Sfard, On two metaphors for learning and the dangers of choosing just one, Educ. Res. 27, 4 (1998).

[12] J. Lave and E. Wenger, Situated Learning: Legitimate Peripheral Participation (Cambridge University Press, Cambridge, England, 1991).

[13] P. W. Irving and E. C. Sayre, Conditions for building a community of practice in an advanced physics laboratory, Phys. Rev. ST Phys. Educ. Res. 10, 010109 (2014).

[14] P. W. Irving and E. C. Sayre, Becoming a physicist: The roles of research, mindsets, and milestones in upper-division student perceptions, Phys. Rev. ST Phys. Educ. Res. 11, 020120 (2015).

[15] E. W. Close, J. Conn, and H. G. Close, Becoming physics people: Development of integrated physics identity through the Learning Assistant experience, Phys. Rev. Phys. Educ. Res. 12, 010109 (2016).

[16] Z. Hazari, G. Sonnert, P. M. Sadler, and M.-C. Shanahan, Connecting high school physics experiences, outcome expectations, physics identity, and physics career choice: A gender study, J. Res. Sci. Teach. 47, 978 (2010).

[17] P. Cobb, Where is the mind? constructivist and sociocultural perspectives on mathematical development, Educ. Res. 23, 13 (1994).

[18] G. Salomon and D. Perkins, Individual and social aspects of learning, Rev. Res. Educ. 23, 1 (1998).

[19] H. Borko, Professional development and teacher learning: Mapping the terrain, Educ. Res. 33, 3 (2004).

[20] J. Dewey, Experience and Education (Kappa Delta Pi, West Lafayette, IN, 1998).

[21] D. L. Ball and D. K. Cohen, Developing practice, developing practitioners: Toward a practice-based theory of professional education, in Teaching as the Learning Profession: Handbook of Policy and Practice, edited by G. Sykes and L. Darling-Hammond (Jossey Bass, San Francisco, 1999), pp. 3-32.

[22] F. Korthagen and B. Lagerwerf, Refraining the relationship between teacher thinking and teacher behaviour: Levels in learning about teaching, Teach. Teach. Educ. 2, 161 (1996).

[23] A. Tigchelaar and F. Korthagen, Deepening the exchange of student teaching experiences: Implications for the pedagogy of teacher education of recent insights into teacher behaviour, Teach. Teach. Educ. 20, 665 (2004).

[24] H. Thornton, Dispositions in action: Do dispositions make a difference in practice?, Teach. Educ. Q. Spring 33, 53 (2006).

[25] H. Fives and M. Buehl, Spring cleaning for the "messy" construct of teachers' beliefs: What are they? Which have been examined? What can they tell us?, in APA
Educational Psychology Handbook: Vol. 2. Individual Differences and Cultural and Contextual Factors, edited by K. R. Harris, S. Graham, and T. C. Urdan (American Psychological Association, Washington, DC, 2012), pp. 471-499.

[26] E. W. Close, L. Seeley, A. D. Robertson, L. S. DeWater, and H. G. Close, Seattle Pacific University: Nurturing preservice physics teachers at a small liberal arts school, in Recruiting and Educating Future Physics Teachers: Case Studies and Effective Practices, edited by C. Sandifer and E. Brewe (American Physical Society, College Park, MD, 2015).

[27] K. Hammerness, L. Darling-Hammond, J. Bransford, D. Berliner, M. Cochran-Smith, M. McDonald, and K. Zeichner, How teachers learn and develop, in Preparing Teachers for a Changing World, edited by L. Darling-Hammond and J. D. Bransford (Jossey Bass, San Francisco, 2005), pp. 358-389.

[28] L. Darling-Hammond, K. Hammerness, P. Grossman, F. Rust, and L. Shulman, The design of teacher education programs, in Preparing Teachers for a Changing World, edited by L. Darling-Hammond and J. Bransford (Jossey-Bass, San Francisco, 2005), pp. 390-441.

[29] S. Feiman-Nemser, From preparation to practice: Designing a continuum to strengthen and sustain teaching, Teachers College Record 103, 1013 (2001).

[30] National council for accreditation of teacher education, Transforming Teacher Education through Clinical Practice: A National Strategy to Prepare Effective Teachers 2010)), http://www.ncate.org/Public/researchreports/ NCAtEinitiatives/BlueribbonPanel/tabid/715/Default.aspx (retrieved 10 January 2017).

[31] E. Whisnant, K. Elliot, and S. Pynchon, A Review of Literature on Beginning Teacher Induction. Prepared for the Center for Strengthening the Teaching Profession (2005).

[32] M. S. Garet, A. C. Porter, L. Desimone, B. F. Birman, and K.S. Yoon, What makes professional development effective? results from a national sample of teachers, Am. Educ. Res. J. 38, 915 (2001).

[33] S. M. Wilson, Professional development for science teachers, Science 340, 310 (2013).

[34] Recruiting and Educating Future Physics Teachers: Case Studies and Effective Practices, edited by C. Sandifer and E. Brewe (American Physical Society, College Park, MD, 2015).

[35] Teacher Education in Physics: Research, Curriculum, and Practice, edited by D. E. Meltzer and P. S. Shaffer (American Physical Society, College Park, MD, 2011).

[36] Ambitious Science Teaching, http:// ambitiousscienceteaching.org/ (retrieved 15 December 2016).

[37] University of Michigan: TeachingWorks, http://www .teachingworks.org/work-of-teaching/ high-leverage-practices (retrieved 15 December 2016).

[38] T. Wubbels, Taking account of student teachers' preconceptions, Teach. Teach. Educ. 8, 137 (1992).

[39] K. E. Gray and V. K. Otero, Analysis of former learning assistants' views on cooperative learning, AIP Conf. Proc. 1179, 149 (2009). 
[40] L. C. McDermott, A perspective on teacher preparation in physics and other sciences: The need for special science courses for teachers, Am. J. Phys. 58, 734 (1990).

[41] L. C. McDermott, Preparing K-12 teachers in physics: Insights from history, experience, and research, Am. J. Phys. 74, 758 (2006).

[42] E. Etkina, Using early teaching experiences, and a professional community to prepare pre-service teachers for every-day classroom challenges, to create habits of student-centered instruction, and to prevent attrition, in Recruiting, and Educating Future Physics Teachers: Case Studies, and Effective Practices, edited by $\mathrm{C}$. Sandifer and E. Brewe (American Physical Society, College Park, MD, 2015).

[43] V. K. Otero, N. D. Finkelstein, R. McCray, and S. J. Pollock, Who is responsible for preparing science teachers?, Science 313, 445 (2006).

[44] L. C. McDermott, Improving high school physics teacher preparation, Phys. Teach. 13, 523 (1975).

[45] D. E. Meltzer, Research on the education of physics teachers, in Teacher Education in Physics: Research, Curriculum, and Practice, edited by D. E. Meltzer and P. S. Shaffer (American Physical Society, College Park, MD, 2011), pp. 3-14.

[46] R. M. Sperandeo-Mineo, C. Fazio, and G. Tarantino, Pedagogical content knowledge development and preservice physics teacher education: A case study, Res. Sci. Educ. 36, 235 (2006).

[47] J. R. Thompson, W. M. Christensen, and Michael C. Wittmann, Preparing future teachers to anticipate student difficulties in physics in a graduate-level course in physics, pedagogy, and education research, Phys. Rev. ST Phys. Educ. Res. 7, 010108 (2011).

[48] D. Peressini, H. Borko, L. Romagnano, E. Knuth, and C. Willis, A conceptual framework for learning to teach secondary mathematics: A situative perspective, Educ. Stud. Math. 56, 67 (2004).

[49] P. Grossman, Learning to Practice: The Design of Clinical Experience in Teacher Preparation (American Association of Colleges for Teacher Education \& National Education Association, Washington, DC, 2010).

[50] V. K. Otero, Nationally scaled model for leveraging course transformation with physics teacher preparation, in Recruiting, and Educating Future Physics Teachers: Case Studies, and Effective Practices, edited by $\mathrm{C}$. Sandifer and E. Brewe (American Physical Society, College Park, MD, 2015), pp. 107-127.

[51] M. S. Sabella, A. D. Robertson, and A. G. Van Duzor, The Teacher Immersion course model: A reform-oriented early teaching experience that capitalizes on collaborations between high schools and universities, in Recruiting and Educating Future Physics Teachers: Case Studies and Effective Practices, edited by C. Sandifer and E. Brewe (American Physical Society, College Park, MD, 2015), pp. 117-127.

[52] M. Windschitl, J. Thompson, and M. Braaten, Ambitious pedagogy by novice teachers: Who benefits from toolsupported collaborative inquiry into practice and why?, Teachers College Record 113, 1311 (2011).
[53] M. W. Curry, Critical friends groups: The possibilities and limitations embedded in teacher professional communities aimed at instructional improvement and school reform, Teachers College Record 110, 733 (2008).

[54] T. Blythe, D. Allen, and B. Schieffelin Powell, Looking Together at Student Work (Teachers College Press, New York, NY, 2015).

[55] T. Hodapp, J. Hehn, and W. Hein, Preparing high-school physics teachers, Phys. Today 62, 40 (2009).

[56] J. Nordine, A. Breidenstein, A. Chapman, and P. McCool, Cultivating outstanding physics teacher mentorship, in Recruiting and Educating Future Physics Teachers: Case Studies and Effective Practices, edited by C. Sandifer and E. Brewe (American Physical Society, College Park, MD, 2015).

[57] J. Dewey, Human Nature and Conduct (Henry Holt and Company, New York, NY, 1922).

[58] Oxford Dictionaries, http://www.oxforddictionaries.com/ (retrieved 15 December 2016).

[59] L. Darling-Hammond, Constructing 21st-Century teacher education, J. Teach. Educ. 57, 300 (2006).

[60] Knowledge Base for the Beginning Teacher, edited by M. C. Reynolds (Pergamon Press, New York, NY, 1989).

[61] D.C. Lortie, Schoolteacher: A Sociological Study (University of Chicago Press, Chicago, 1975).

[62] M. Pajares, Teachers' beliefs and educational research: Cleaning up a messy construct, Rev. Educ. Res. 62, 307 (1992).

[63] A. G. Thompson, Teachers' beliefs and conceptions: A synthesis of the research, in Handbook of Research on Mathematics Teaching and Learning: A Project of the National Council of Teachers of Mathematics, edited by D. Grouws (Macmillan Publishing, New York, NY, 1992), pp. 127-146.

[64] L. A. Bryan, Nestedness of beliefs: Examining a prospective elementary teacher's belief system about science teaching and learning, J. Res. Sci. Teach. 40, 835 (2003).

[65] P. J. Nelsen, Intelligent Dispositions: Dewey, Habits and Inquiry in Teacher Education, J. Teach. Educ. 66, 86 (2015).

[66] Re-Examining Pedagogical Content Knowledge in Science Education, edited by A. Berry, P. Friedrichsen, and J. Loughran (Routledge, New York, NY, 2015).

[67] R. Bullough, Pedagogical content knowledge circa 1907 and 1987: A study in the history of an idea, Teach. Teach. Educ. 17, 655 (2001).

[68] L. Shulman, Those who understand: Knowledge growth in teaching, Educ. Res. 15, 4 (1986).

[69] C. Hernandez and A. Rushby, A new course for physics teachers in Peru, Phys. Teach. 11, 401 (1973).

[70] D. Schön, The Reflective Practitioner: How Professionals Think in Action, 1st ed. (Basic Books, New York, 1983).

[71] A. H. Schoenfeld, How We Think: A Theory of Goal-Oriented Decision Making and Its Educational Applications (Routledge, New York, NY, 2010).

[72] A. H. Schoenfeld, Toward a theory of teaching-in-context, Issues Educ. 4, 1 (1998).

[73] J. A. Bargh, Automaticity in action: The unconscious as repository of chronic goals, and motives, in The Psychology of Action: Linking Cognition, and Motivation to 
Behavior, edited by P. Gollwitzer and J. A. Bargh (Guilford Press, New York, NY, 1996), pp. 457-481.

[74] E. Wenger, Communities of Practice: Learning, Meaning, and Identity (Cambridge University Press, Cambridge, England, 1998).

[75] G. Holton and S. G. Brush, Physics, the Human Adventure (Rutgers University Press, New Brunswick, NJ, 2001).

[76] M. Poklinek Čančula, G. Planinšič, and E. Etkina, Analyzing patterns in experts' approaches to solving experimental problems, Am. J. Phys. 83, 366 (2015).

[77] C. Singh, When physical intuition fails, Am. J. Phys. 70, 1103 (2002).

[78] M. J. Lattery, Signature pedagogies in introductory physics, in Exploring Signature Pedagogies: Approaches to Teaching Disciplinary Habits of Mind, edited by R. A. R. Gurung, N. L. Chick, and A. Haynie (Stylus Publishing, Sterling, VA, 2009), pp. 289-294.

[79] E. Etkina, A. Van Heuvelen, S. White-Brahmia, D. Brookes, M. Gentile, S. Murthy, D. Rosengrant, and A. Warren, Scientific abilities and their assessment, Phys. Rev. ST Phys. Educ. Res. 2, 020103 (2006).

[80] A. Van Heuvelen, Learning to think like a physicist: A review of research-based instructional strategies, Am. J. Phys. 59, 891 (1991).

[81] A. B. Arons, A Guide to Introductory Physics Teaching (Wiley, New York, NY, 1990).

[82] R. A. R. Gurung, N. L. Chick, and A. Haynie, Exploring Signature Pedagogies: Approaches to Teaching Disciplinary Habits of Mind (Stylus Publishing, Sterling, VA, 2009).

[83] S. Brahmia, Ph.D. thesis, Rutgers University, Graduate School of Education, 2014.

[84] T. J. Bing and E. F. Redish, The cognitive blending of mathematics and physics knowledge, AIP Conf. Proc. 883, 26 (2007).

[85] S. Brahmia and A. Boudreaux, Exploring student understanding of the negative sign in introductory physics contexts, in Proceedings of the 19th Annual Conference on Research in Undergraduate Mathematics Education (Pittsburgh, PA, 2016).

[86] S. Brahmia and A. Boudreaux, Signed quantities: Mathematics based majors struggle to make meaning, in Proceedings of the 20th Annual Conference on Research in Undergraduate Mathematics Education (San Diego, CA, 2017).

[87] P. Cobb, Where is the mind? Constructivist and sociocultural perspectives on mathematical development, Educ. Res. 23, 13 (1994).

[88] E. Etkina, Millikan award lecture: Students of physicsListeners, observers, or collaborative participants in physics scientific practices?, Am. J. Phys. 83, 669 (2015).

[89] D. Brookes and E. Etkina, "Force," ontology, and language, Phys. Rev. ST Phys. Educ. Res. 5, 010110 (2009).

[90] L. C. McDermott, Millikan Lecture 1990: What we teach and what is learned-Closing the gap, Am. J. Phys. 59, 301 (1991).

[91] P. W. Laws, Millikan Lecture 1996: Promoting active learning based on physics education research in introductory physics courses, Am. J. Phys. 65, 14 (1997).
[92] J.E. Zull, The Art of Changing the Brain: Enriching Teaching by Exploring the Biology of Learning (Stylus Publishing, Sterling, VA, 2002).

[93] J. Jackson, L. Dukerich, and D. Hestenes, Modeling instruction: An effective model for science education, Science Educator 17, 10 (2008).

[94] How People Learn: Brain, Mind, Experience, and School, edited by J. D. Bransford, A. L. Brown, and R. R. Cocking (National Academy Press, Washington, DC, 2000).

[95] R. M. Ryan and E. L. Deci, Self-Determination theory and the facilitation of intrinsic motivation, social development, and well-being, Am. Psychol. 55, 68 (2000).

[96] B. L. Sherin, How students understand physics equations, Cognit. Instr. 19, 479 (2001).

[97] C. J. B. MacMillan and J. Garrison, An erotetic concept of teaching, in A Logical Theory of Teaching (Springer Netherlands, 1988), pp. 21-40.

[98] Responsive Teaching in Science and Mathematics, edited by A. Robertson, R. E. Scherr, and D. Hammer (Routledge, New York, 2016).

[99] R. S. Russ, R. E. Scherr, D. Hammer, and J. Mikeska, Recognizing mechanistic reasoning in student scientific inquiry: A framework for discourse analysis developed from philosophy of science, Sci. Educ. 92, 499 (2008).

[100] M. Braaten and M. Windschitl, Working toward a stronger conceptualization of scientific explanation for science education, Sci. Educ. 95, 639 (2011).

[101] C. Danielson, Enhancing Professional Practice: A Framework for Teaching (Association for Supervision and Curriculum Development, Alexandria, VA, 1996).

[102] P. Black and D. Wiliam, Assessment and Classroom Learning, Assess. Educ. Princ. Policy Pract. 5, 7 (1998).

[103] D. T. Brookes and E. Etkina, The Importance of Language in Students' Reasoning About Heat in Thermodynamic Processes, Int. J. Sci. Educ. 37, 759 (2015).

[104] D. Hammer, Misconceptions or P-Prims: How may alternative perspectives of cognitive structure influence instructional perceptions and intentions, J. Learn. Sci. 5, 97 (1996).

[105] D. Hammer, Student resources for learning introductory physics, Am. J. Phys. 68, S52 (2000).

[106] D. E. Meltzer (private communication).

[107] P. E. Simmons et al., Beginning teachers: Beliefs and classroom actions, J. Res. Sci. Teach. 36, 930 (1999).

[108] R. Yerrick, H. Parke, and J. Nugent, Struggling to promote deeply rooted change: The "filtering effect" of teachers' beliefs on understanding transformational views of teaching science, Sci. Educ. 81, 137 (1997).

[109] K. Bingimlas and M. Hanrahan, The relationship between teachers' beliefs and their practice: How the literature can inform science education reformers and researchers, in Contemporary Science Education Research: International Perspectives, edited by M.F. Tasar and G. Cakmakci (Pegem Akademi, Ankara, Turkey, 2010), pp. 415-422.

[110] T. L. Good, Two decades of research on teacher expectations: Findings and future directions, J. Teach. Educ. 38, 32 (1987).

[111] R. W. Roeser and J. S. Eccles, Adolescents' perceptions of middle school: Relation to longitudinal changes in 
academic and psychological adjustment, J. Res. Adolesc. 8, 123 (1998).

[112] J.S. Eccles and C. Midgley, Changes in academic motivation and self-perception during early adolescence, in From Childhood to Adolescence. A Transitional Period?, edited by R. Montemayor, G. R. Adams, and T. P. Gullotta (Sage Publications, Newbury Park, London, New Delhi, 1990), pp. 134-155.

[113] J. S. Eccles, C. Midgley, A. Wigfield, C. M. Buchanan, D. Reuman, C. Flanagan, and D. M. Iver, Development during adolescence. The impact of stage-environment fit on young adolescents' experiences in schools and in families, Am. Psychol. 48, 90 (1993).

[114] V. Shekoyan and E. Etkina, Introducing Ill-structured problems in introductory physics recitations, AIP Conf. Proc. 951, 192 (2007).

[115] V. Shekoyan, Ph.D. thesis, Rutgers University, 2009.

[116] T. J. Bing and E. F. Redish, Analyzing problem solving using math in physics: Epistemological framing via warrants, Phys. Rev. ST Phys. Educ. Res. 5, 020108 (2009).

[117] T. Bing, Ph.D. thesis, University of Maryland, 2008.

[118] E. Cohen and S.E. Kanim, Factors influencing the algebra "reversal error", Am. J. Phys. 73, 1072 (2005).

[119] L.C. McDermott and E. F. Redish, Resource letter: PER-1: Physics education research, Am. J. Phys. 67, 755 (1999).

[120] R. Duit, Bibliography-Students' and Teachers' Conceptions and Science Education, http://archiv.ipn.uni-kiel .de/stcse/, 2009.

[121] PhET Interactive Simulations, https://phet.colorado.edu/ (retrieved 15 December 2016).

[122] Physics Union Mathematics (PUM), http://pum.rutgers .edu/ (retrieved 15 December 2016).

[123] 122American Modeling Teachers Association, http:// modelinginstruction.org/ (retrieved 15 December 2016).

[124] Diagnoser, http://www.diagnoser.com/ (retrieved 15 December 2016).

[125] D. Hestenes, M. Wells, and G. Swackhamer, Force concept inventory, Phys. Teach. 30, 141 (1992).

[126] D. P. Maloney, T. L. O'Kuma, C. J. Hieggelke, and A. Van Heuvelen, Surveying students' conceptual knowledge of electricity and magnetism, Am. J. Phys. 69, S12 (2001).

[127] C. J. Hieggelke, S. Kanim, D. P. Maloney, and T. L. O'Kuma, TIPERs: Sensemaking Tasks for Introductory Physics (Pearson Addison-Wesley, San Francisco, 2013).

[128] Physics Instructional Resource Association (PIRA), www.pira-online.org (retrieved 15 December 2016).

[129] D. J. Boyd, P. L. Grossman, H. Lankford, S. Loeb, and J. Wyckoff, Teacher preparation and student achievement, Educ. Eval. Policy Anal. 31, 416 (2009).
[130] D. T. Brookes and E. Etkina, Using conceptual metaphor and functional grammar to explore how language used in physics affects student learning, Phys. Rev. ST Phys. Educ. Res. 3, 010105 (2007).

[131] A. Madsen, S. B. McKagan, and E. C. Sayre, How physics instruction impacts students' beliefs about learning physics, Phys. Rev. ST Phys. Educ. Res. 11, 010115 (2015).

[132] M. Plisch, J. C. Blickenstaff, and J. Anderson, The PhysTEC Teacher-in-Residence: What an expert high school teacher can bring to a physics education program, in Recruiting and Educating Future Physics Teachers: Case Studies and Effective Practices, edited by $\mathrm{C}$. Sandifer and E. Brewe (American Physical Society, College Park, MD, 2015), pp. 225-244.

[133] P. Lally, C. H. M. van Jaarsveld, H. W. W. Potts, and J. Wardle, How are habits formed: Modelling habit formation in the real world, European Journal of social psychology 40, 998 (2010).

[134] C. J. Wenning and R. E. Vieyra, Teaching High School Physics, Volume 1 (Amazon Digital Services, Inc., 2015).

[135] C. J. Wenning and R. E. Vieyra, Teaching High School Physics, Volume 2 (Amazon Digital Services, Inc., 2015).

[136] C. J. Wenning and R. E. Vieyra, Teaching High School Physics, Volume 3 (Amazon Digital Services, Inc., 2015).

[137] I. T. Koponen and T. Mäntylä, Generative role of experiments in physics and in teaching physics: A suggestion for epistemological reconstruction, Sci. Educ. 15, 31 (2006).

[138] A. D. Churukian and L. E. McNeil, Joining hands to establish a teacher training program: An example from a major research university, in Recruiting and Educating Future Physics Teachers: Case Studies and Effective Practices, edited by C. Sandifer and E. Brewe (American Physical Society, College Park, MD, 2015), pp. 275-282.

[139] P. Grossman, S. Wineburg, and S. Woolworth, Toward a theory of teacher community, Teachers College Record 103, 942 (2001).

[140] S. Vokos and T. Hodapp, Characteristics of thriving physics teacher education programs, in Recruiting and Educating Future Physics Teachers: Case Studies and Effective Practices, edited by C. Sandifer and E. Brewe (American Physical Society, College Park, MD, 2015).

[141] D. L. Messina, Ph.D. thesis, University of Washington, 2008.

[142] D. L. Messina, Learning and Teaching Through Inquiry: Bringing change to the science classroom, Science and Mathematics Education Conference Proceedings (Dublin, Ireland, 2010), pp. 147-153. 